\title{
Dysidenin from the Marine Sponge Citronia sp. Affects the Motility and Morphology of Haemonchus contortus Larvae In Vitro
}

\author{
Kelsey S. Ramage ${ }^{1}{ }^{\mathbb{D}}$, Aya C. Taki ${ }^{2}{ }^{\mathbb{D}}$, Kah Yean Lum ${ }^{1}$, Sasha Hayes ${ }^{1}$, Joseph J. Byrne ${ }^{2}$, Tao Wang ${ }^{2} \mathbb{D}$, \\ Andreas Hofmann 2,3 ${ }^{\mathbb{D}}$, Merrick G. Ekins ${ }^{1,4}$, Jonathan M. White ${ }^{5}$, Abdul Jabbar ${ }^{2} \mathbb{D}$, Rohan A. Davis ${ }^{1, *(\mathbb{D})}$ \\ and Robin B. Gasser $2, *$ (i)
}

Citation: Ramage, K.S.; Taki, A.C.; Lum, K.Y.; Hayes, S.; Byrne, J.J.; Wang, T.; Hofmann, A.; Ekins, M.G.; White, J.M.; Jabbar, A.; et al. Dysidenin from the Marine Sponge Citronia sp. Affects the Motility and Morphology of Haemonchus contortus Larvae In Vitro. Mar. Drugs 2021, 19, 698. https://doi.org/10.3390/ md19120698

Academic Editors: Ali Al-Mourabit and Sylvain Petek

Received: 5 November 2021

Accepted: 2 December 2021

Published: 9 December 2021

Publisher's Note: MDPI stays neutral with regard to jurisdictional claims in published maps and institutional affiliations.

Copyright: (c) 2021 by the authors. Licensee MDPI, Basel, Switzerland. This article is an open access article distributed under the terms and conditions of the Creative Commons Attribution (CC BY) license (https:/ / creativecommons.org/licenses/by/ $4.0 /)$.
1 Griffith Institute for Drug Discovery, School of Environment and Science, Griffith University, Brisbane QLD 4111, Australia; kelsey.ramage@griffithuni.edu.au (K.S.R.); k.lum@griffith.edu.au (K.Y.L.); sasha.hayes2@griffithuni.edu.au (S.H.); merrick.ekins@qm.qld.gov.au (M.G.E.)

2 Department of Veterinary Biosciences, Faculty of Veterinary and Agricultural Sciences, Melbourne Veterinary School, The University of Melbourne, Parkville, VIC 3010, Australia; aya.taki@unimelb.edu.au (A.C.T.); byrnej1@unimelb.edu.au (J.J.B.); tao.wang1@unimelb.edu.au (T.W.); a.hofmann@structuralchemistry.org (A.H.); jabbara@unimelb.edu.au (A.J.)

3 Max Rubner-Institut, Federal Research Institute of Nutrition and Food, 95326 Kulmbach, Germany

4 Queensland Museum, South Brisbane, QLD 4101, Australia

5 School of Chemistry and Bio21 Institute, The University of Melbourne, Parkville, VIC 3010, Australia; whitejm@unimelb.edu.au

* Correspondence: r.davis@griffith.edu.au (R.A.D.); robinbg@unimelb.edu.au (R.B.G.)
Abstract: High-throughput screening of the NatureBank marine extract library $(n=7616)$ using a phenotypic assay for the parasitic nematode Haemonchus contortus identified an active extract derived from the Australian marine sponge Citronia sp. Bioassay-guided fractionation of the $\mathrm{CH}_{2} \mathrm{Cl}_{2} / \mathrm{MeOH}$ extract from Citronia sp. resulted in the purification of two known hexachlorinated peptides, dysidenin (1) and dysideathiazole (2). Compound 1 inhibited the growth/development of H. contortus larvae and induced multiple phenotypic changes, including a lethal evisceration (Evi) phenotype and/or somatic cell and tissue destruction. This is the first report of anthelmintic activity for these rare and unique polychlorinated peptides.

Keywords: Haemonchus contortus; parasitic nematode; nematocidal; marine natural products; NatureBank; biodiscovery; extract library; sponge; Citronia; dysidenin; dysideathiazole

\section{Introduction}

Parasitic nematodes cause significant disease in livestock and affect hundreds of millions of livestock animals, such as sheep, goats, cattle and deer worldwide [1,2]. In most parts of the world, Haemonchus contortus (order Strongylida) is one of the most impactful parasites of small ruminants due to its blood feeding activity and pathogenic effects, leading to anaemia, reduced wool production and sometimes death [1,2]. Like most other strongylid nematodes, $H$. contortus is transmitted orally via the ingestion of grass contaminated with infective third-stage larvae (L3s). Following ingestion by the ruminant host, L3s exsheath (to become xL3s) and then develop to dioecious fourth-stage larvae (L4s) and adults within the stomach (abomasum) [2]. While a relatively small number of anthelmintic (antihelminth) drugs and a recently developed vaccine (Barbervax) against $H$. contortus are currently in use, resistance to anthelmintics has been widely reported in this and related parasites, and the efficacy of the vaccine can vary $[3,4]$. The heavy reliance on anthelmintic agents in parasite control programs, despite growing resistance, means that there is an imperative to discover and develop novel anthelmintics.

Some of our previous anthelmintic discovery work has identified nematocidal/ nematostatic candidates in natural product extracts derived from plants or marine in- 
vertebrates $[5,6]$. To expand our biodiscovery efforts, we recently screened a collection of extracts $(n=7616)$ derived from marine invertebrates isolated from Australian waters in an established high throughput screening (HTS) assay for in vitro activity against Haemonchus contortus larvae [7]. We identified 58 active extracts that markedly reduced larval motility, achieving an overall "hit rate" of $\sim 0.8 \%$ [7]. Of these 58 extracts, 16 significantly inhibited larval development and/or induced abnormal larval phenotypes. The majority of active extracts (54) were from sponges. ${ }^{1} \mathrm{H}$ NMR fingerprinting was employed to dereplicate hits and to prioritise 29 samples for future chemical investigations. Herein, we report the chemical and biological investigations of a singleton hit extract from a species of Citronia that was identified in our HTS effort. Citronia is a poorly studied genus of sponge, with only two natural product chemistry papers reported to date. In one study, dysinosin A was isolated from Citronia astra, and found to act as a potent inhibitor of the blood coagulation cascade factor VIIa and an inhibitor of the serine protease thrombin [8]; in a subsequent investigation, citronamides A and B were isolated from the same sponge species and shown to have antifungal activity [9]. This paper constitutes the first investigation of anthelmintic activity from this sponge genus.

\section{Results and Discussion}

\subsection{Bioassay-Guided Fractionation of the Citronia Extract}

In order to identify the marine natural product(s) responsible for the anthelmintic activity of the extract from Citronia sp., we initiated an extraction and bioassay-guided fractionation investigation. The freeze-dried, ground Citronia specimen was sequentially extracted with $n$-hexanes, $\mathrm{CH}_{2} \mathrm{Cl}_{2}: \mathrm{MeOH}(8: 2)$ and $\mathrm{MeOH}$. The highly lipophilic hexanesoluble extract was discarded, and all the $\mathrm{CH}_{2} \mathrm{Cl}_{2}$ and $\mathrm{MeOH}$ extracts were combined and fractionated by reversed-phase $\mathrm{C}_{18} \mathrm{HPLC}\left(\mathrm{H}_{2} \mathrm{O} / \mathrm{MeOH} / 0.1 \%\right.$ TFA) (Figure S1) [10], which yielded 60 fractions that were then evaluated for anthelmintic activity in the established xL3 motility assay [11].

Fractions 50 to 55 and 57 each caused limited motility reduction $(\leq 59 \%)$, but induced a curved (Cur) phenotype, with fraction 50 also inducing an eviscerated (Evi, lethal) phenotype in $\sim 33.3 \%$ of larvae. $\mathrm{C}_{18}$ HPLC fractionation $\left(\mathrm{H}_{2} \mathrm{O} / \mathrm{MeOH} / 0.1 \%\right.$ TFA) of fraction 50 yielded two major hexachlorinated compounds. Comparison of 1D NMR, UHPLC-MS (Figures S1-S8) and specific rotation data identified these compounds as the previously reported Dysideidae-derived metabolites, dysidenin (1) and dysideathiazole (2) (Figure 1) [12-14]; both compounds have had their absolute configurations determined, albeit via convoluted paths. For example, whilst the crystal structure of dysideathiazole (2) was first reported in the original isolation paper by Unson et al. [12], the data obtained did not allow unambiguous absolute configuration assignments to be made. However, chemical degradation of dysideathiazole and subsequent heavy atom derivatisation studies resulted in the absolute stereochemistry being determined for this molecule [12,13]. Fortuitously, during our isolation studies X-ray quality crystals of 2 were obtained. Subsequent low temperature data using $\mathrm{Cu}-\mathrm{K} \alpha$ radiation out to higher resolution $\left(2 \theta=154.6^{\circ}\right)$, gave a highquality structure with a Flack parameter of 0.002(12) that enabled the absolute configuration of the natural product to be assigned (i.e., $2 \mathrm{~S}, 5 \mathrm{~S}$ and $7 \mathrm{~S}$ ); our data agreed favourably with the earlier assignment [12,14]. The thermal ellipsoid plot for dysideathiazole (2) is presented in Figure 2, which depicts 50\% ellipsoids. Furthermore, from our studies it was noted that crystal packing for dysideathiazole is characterised by infinite chains of molecules related by a $2{ }_{1}$ screw axis extending down the a-axis and held together by $\mathrm{N}-\mathrm{H} \ldots$. O hydrogen bonds and $\mathrm{N} \ldots \mathrm{Cl}$ halogen bonds (Figure S8). 
<smiles>C[C@H](NC(=O)[C@@H](C[C@H](C)C(Cl)(Cl)Cl)N(C)C(=O)C[C@@H](C)C(Cl)(Cl)Cl)c1nccs1</smiles>

1<smiles>C[C@@H](C[C@@H](NC(=O)C[C@@H](C)C(Cl)(Cl)Cl)c1nccs1)C(Cl)(Cl)Cl</smiles>

2

Figure 1. Chemical structures of dysidenin (1) and dysideathiazole (2).

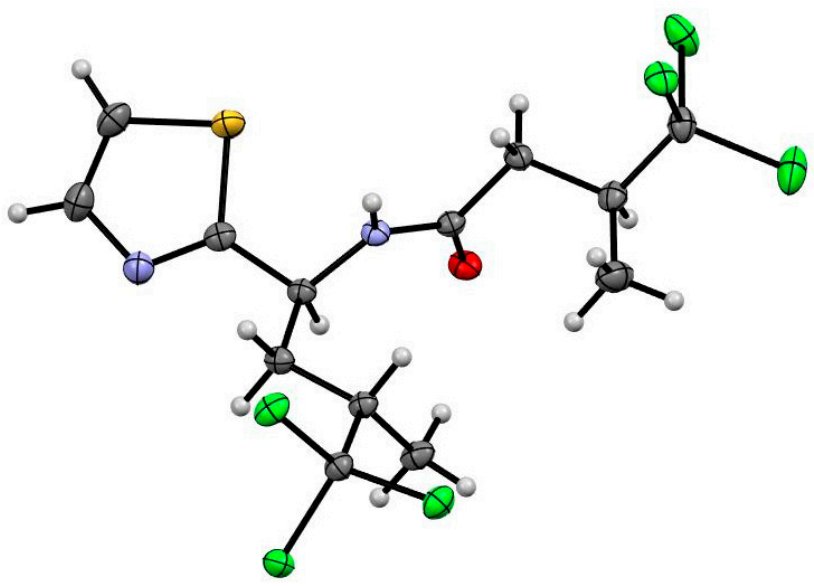

Figure 2. ORTEP drawing of dysideathiazole (2).

\subsection{Biological Evaluation of Dysidenin (1) and Dysideathiazole (2) Purified from Citronia}

The two purified compounds, dysidenin (1) and dysideathiazole (2) (cf. Figure 1), were tested at a concentration of $100 \mu \mathrm{M}$ for their anthelmintic effect on xL3s (in transition to L4s) and on in vitro-raised L4s. Although neither of the two compounds significantly reduced xL3 motility at 72 h, 1 inhibited larval development (from xL3 to L4) by 58\% and induced abnormal phenotypes in $65 \%$ of worms (43\% Cur, 14\% Evi and 8\% skinny (Ski)) at $168 \mathrm{~h}$ (Table 1). However, 2 did not induce developmental inhibition or phenotypic change, indicating that the active component within fraction 50 is dysidenin (1). When tested on in vitro-raised L4s, dysidenin (1) and dysideathiazole (2) reduced their motility by $61 \%$ and $25 \%$, respectively, after $72 \mathrm{~h}$ of incubation (Table 1). Both compounds 1 and 2 induced a Ski phenotype in $50 \%$ and $28 \%$ of in vitro-raised L4s (Table 1), with IC $_{50}$ values of 31 and $62 \mu \mathrm{M}$, respectively. This phenotype has previously been associated with damage of subcuticular musculature and mitochondria [15]. In addition, all L4s exposed to $100 \mu \mathrm{M}$ of 1 exhibited marked destruction of somatic (gut and muscle) cells and tissue disintegration (Figure 3). Additional work is needed to evaluate the effect of these pure compounds on adult females and males of $H$. contortus isolated from, or in, an infected host animal (e.g., sheep).

This is the first report of anthelmintic activity of extracts from Citronia, and of dysidenin (1) and dysideathiazole (2) from any species other than Dysidea herbacea [12,13], although evidence of other biological activity has been reported for these polychlorinated peptides. Previous studies [16-19] demonstrated that dysidenin (1) and its C-5 epimer isodysidenin reduce iodide transport into thyroid tissues through an incomplete, reversible inhibition of mammalian sodium iodide symporters. Published findings [16,17] suggest that these two compounds may be pseudo-competitive for iodide in these symporters. Some moderate, but non-selective, inhibitory activity has been reported for dysidenin towards platelet-type 12-human lipoxygenase [20]. More recently, dysidenin (1) has been shown to inhibit bone morphogenetic protein-induced alkaline phosphatase in 
$\mathrm{C} 2 \mathrm{C} 12(\mathrm{R} 206 \mathrm{H})$ mouse leg muscle cells with an $\mathrm{IC}_{50}$ value of $2.3 \mu \mathrm{M}$, but no toxicity to mammalian cells (up to $21.4 \mu \mathrm{M}$ ) has been observed [21]. While an $\mathrm{LD}_{50}$ of $5 \mathrm{mg} / \mathrm{L}$ (in water) was reported for the guppy fish (Lebistes reticulatus) [22] as evidence for 'general' toxicity, the methodology employed was not described by the authors, such that this claim warrants re-investigation.

The phenotypic changes induced here by dysidenin (1) in H. contortus larvae, particularly the lethal Evi phenotype in xL3s, and the somatic tissue disintegration and cell destruction in L4s, suggest that this compound has a unique mechanism of action, which requires future elucidation.

Table 1. In vitro-activities of dysidenin (1) and dysideathiazole (2) against exsheathed third-stage larvae (xL3) and against in vitro-raised fourth-stage larvae (L4) of Haemonchus contortus. Maximum inhibitory values of each compound on the larval motility after $72 \mathrm{~h}$ incubation, the larval (xL3) development (in transition to L4) after $168 \mathrm{~h}$ and induced abnormal phenotypes at $72 \mathrm{~h}$ (in vitro-raised L4s) or $168 \mathrm{~h}(\mathrm{xL3s} / \mathrm{L} 4 \mathrm{~s})$ are presented in reference to the values of control compound (monepantel) obtained under the same assay condition. Three independent experiments were conducted in all cases.

\begin{tabular}{|c|c|c|c|c|c|}
\hline & \multicolumn{3}{|c|}{ xL3s } & \multicolumn{2}{|c|}{ In Vitro-Raised L4s } \\
\hline & $\begin{array}{l}\text { Motility } \\
\text { Inhibition } \\
\quad(72 \mathrm{~h})\end{array}$ & $\begin{array}{l}\text { Development } \\
\text { Inhibition } \\
(168 \mathrm{~h})\end{array}$ & $\begin{array}{c}\text { Abnormal Phenotype(s) } \\
\text { Detected } \\
(168 \mathrm{~h})\end{array}$ & $\begin{array}{l}\text { Motility } \\
\text { Inhibition } \\
\quad(72 \mathrm{~h})\end{array}$ & $\begin{array}{c}\text { Abnormal Phenotype } \\
\text { Detected } \\
(72 \mathrm{~h})\end{array}$ \\
\hline Dysidenin (1) & nd & $58 \%$ & Cur $(43 \%), \operatorname{Evi}(14 \%)$, Ski $(8 \%)$ & $61 \%$ & Ski $(50 \%)$ \\
\hline Dysideathiazole (2) & nd & nd & nd & $25 \%$ & Ski $(28 \%)$ \\
\hline Monepantel & $81 \%$ & $100 \%$ & $\operatorname{Coi}(90 \%)$ & $70 \%$ & Ski $(78 \%)$ \\
\hline
\end{tabular}

nd, not detectable; Cur, curved; Coi, coiled; Evi, evisceration; or Ski, skinny (phenotypes).

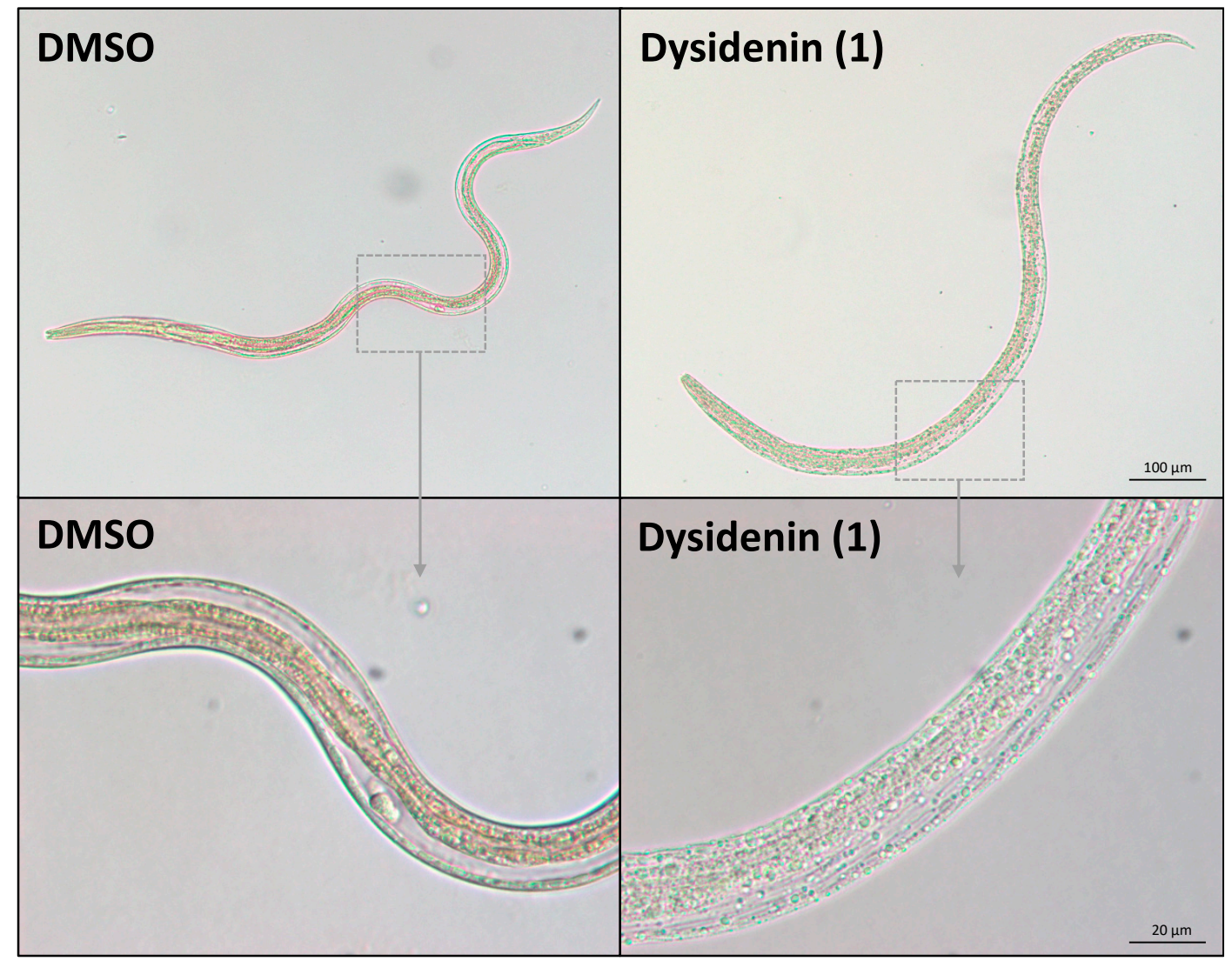

Figure 3. Photomicrographs of in vitro-raised fourth-stage larvae (L4s) of Haemonchus contortus treated with $100 \mu \mathrm{M}$ of dysidenin (1) compared with a negative (DMSO-only) control, captured at 200-times (top) and 1000-times (bottom) magnification. Somatic (gut and muscle) cell destruction and tissue disintegration are visible (bottom right). 


\section{Materials and Methods}

\subsection{Chemistry Procedures}

Melting points were measured using a Cole-Parmer apparatus (Antylia Scientific, Chicago, IL, USA) and were uncorrected. Specific rotations were recorded using a JASCO P-1020 polarimeter (Japan Spectroscopic Company, Tokyo, Japan). NMR spectra were recorded at $25{ }^{\circ} \mathrm{C}$ on a Bruker AVANCE III HD $800 \mathrm{MHz}$ NMR spectrometer (Bruker, Billerica, MA, USA), equipped with a cryoprobe. The ${ }^{1} \mathrm{H}$ and ${ }^{13} \mathrm{C}$ chemical shifts were referenced to solvent peaks for $\mathrm{CDCl}_{3}\left(\delta_{\mathrm{H}} 7.26, \delta_{\mathrm{C}} 77.16\right)$. LRESIMS data were recorded on a Dionex Ultimate 3000 RS UHPLC (Thermo Fisher Scientific, Waltham, MA, USA) coupled to an ISQEC single quadruple ESI mass spectrometer (Thermo Fisher Scientific). Davisil $C_{18}$-bonded silica (35-70 $\mu \mathrm{m}, 60 \AA$ ) were used for pre-adsorption prior to reversedphase HPLC. The chromatography resin with pre-adsorbed material was packed into a stainless-steel guard Davisil cartridge $(10 \times 30 \mathrm{~mm})$ and then attached to an HPLC column prior to fractionation. A Dionex Ultimate LC system was used for HPLC separations. Betasil $C_{18}$-bonded silica ( $5 \mu \mathrm{m}, 100 \AA, 150 \times 21.2 \mathrm{~mm}$; Thermo Fisher Scientific) or Luna $\mathrm{C}_{18}$-bonded silica $(5 \mu \mathrm{m}, 90-110 \AA, 250 \times 10 \mathrm{~mm}$; Phenomenex, Torrance, CA, USA) columns were used for reversed-phase HPLC separations. The ground sponge material was extracted at room temperature by continuous agitation using an orbital shaker (Bioline, Edwards Instrument Company, Narellan, NSW, Australia) set at 200 rpm. Solvents were removed from crude marine extracts with a Buchi R-144 rotary evaporator and from HPLC fractions using a GeneVac XL4 centrifugal evaporator. All solvents used for chromatography, mass spectrometry and polarimetry were HPLC grade and sourced from Honeywell Burdick \& Jackson or Lab-Scan and were HPLC grade; $\mathrm{H}_{2} \mathrm{O}$ was filtered using an Arium ${ }^{\circledR}$ Pro VF ultrapure water system (Sartorius, Göttingen, Germany).

\subsection{Collection of Sponge Material}

The sponge Citronia sp. was collected by SCUBA diving $(1.8 \mathrm{~m})$ from Ribbon Reef, Queensland, Australia, in November 2005. The sponge sample was immediately frozen at $-20{ }^{\circ} \mathrm{C}$ upon collection and subsequently transported to the Griffith Institute for Drug Discovery, where the material was freeze-dried and ground into a fine powder and then stored in the NatureBank biota repository. A voucher specimen of Citronia sp. (QM G325135; operational taxonomic unit-OTU3186) has been deposited at the Queensland Museum, South Brisbane, Queensland, Australia.

\subsection{Fractionation of the Citronia Extract}

The freeze-dried and ground specimen of Citronia sp. (900 mg) was sequentially extracted with $n$-hexane $(21 \mathrm{~mL}), \mathrm{CH}_{2} \mathrm{Cl}_{2}: \mathrm{MeOH}(8: 2,21 \mathrm{~mL})$ and $\mathrm{MeOH}(39 \mathrm{~mL})$ at room temperature. The $n$-hexane extract was discarded, since it contained highly lipophilic $(\log p>5)$ material, while all $\mathrm{CH}_{2} \mathrm{Cl}_{2}$ and $\mathrm{MeOH}$ extracts were combined and dried to give a crude extract $(279 \mathrm{mg})$. Half of this extract was pre-adsorbed to $\mathrm{C}_{18}$-bonded silica $(\sim 1 \mathrm{~g})$ and then packed into a guard cartridge for separation using a $\mathrm{C}_{18}$-bonded silica Betasil HPLC column. Isocratic solvent conditions of $90 \% \mathrm{H}_{2} \mathrm{O}(0.1 \%$ trifluoroacetic acid, TFA) $/ 10 \% \mathrm{MeOH}(0.1 \%$ TFA) were employed for the first $10 \mathrm{~min}$, followed by a linear gradient to $100 \% \mathrm{MeOH}(0.1 \%$ TFA) over $40 \mathrm{~min}$, and a final isocratic condition of $100 \%$ $\mathrm{MeOH}(0.1 \%$ TFA) for additional $10 \mathrm{~min}$ at a flow rate of $9 \mathrm{~mL} / \mathrm{min}$, collecting at $1 \mathrm{~min}$ intervals. In total, 60 fractions were collected.

From each of the 60 fractions, aliquots $(2000 \mu \mathrm{ge} / \mu \mathrm{L})$ were transferred into a 384-well microtitre plate and tested in an established high throughput assay for $H$. contortus (see Section 3.6. Of the fractions that contained anthelmintic entities (nos. 50-55 and 57), the most abundant fraction (no. 50; $21 \mathrm{mg}$ ) was further purified by HPLC using a $\mathrm{C}_{18}$-bonded silica Luna column with isocratic solvent conditions of $90 \% \mathrm{H}_{2} \mathrm{O}(0.1 \%$ TFA $) / 10 \% \mathrm{MeOH}$ ( $0.1 \%$ TFA), employed for the initial $10 \mathrm{~min}$, followed by a linear gradient to $100 \% \mathrm{MeOH}$ (0.1\% TFA) over $40 \mathrm{~min}$, and, lastly, $100 \% \mathrm{MeOH}(0.1 \%$ TFA) for additional $10 \mathrm{~min}$ at a flow rate of $4 \mathrm{~mL} / \mathrm{min}$; $1 \mathrm{~min}$ fractions were collected. This yielded the previously 
described marine natural products dysidenin $\left(\mathbf{1}, 3.0 \mathrm{mg}, 0.33 \%\right.$ dry $\left.\mathrm{wt}, \mathrm{t}_{\mathrm{R}}=35-36 \mathrm{~min}\right)$ and dysideathiazole $\left(2,2.0 \mathrm{mg}, 0.22 \%\right.$ dry $\left.\mathrm{wt}, \mathrm{t}_{\mathrm{R}}=33-34 \mathrm{~min}\right)$, in high purity $(>95 \%)$.

Dysidenin (1): White amorphous solid; $[\alpha]_{D}^{24.3}-89.0^{\circ}\left(c 0.365, \mathrm{CHCl}_{3}\right)$, lit. $[\alpha]_{D}$ $-98^{\circ}\left(\right.$ c $\left.0.5, \mathrm{CHCl}_{3}\right)[12],{ }^{1} \mathrm{H}$ and ${ }^{13} \mathrm{C}$ NMR and UHPLC-MS data (see Figures S2-S4).

Dysideathiazole (2): Clear needles ( $25 \%$ EtOAc $/ 75 \% n$-hexane); $M=461.04 \mathrm{~g} / \mathrm{mol}$; mp 178-182 ${ }^{\circ} \mathrm{C}$, lit. mp $176-177^{\circ} \mathrm{C}[12],[\alpha]_{D}^{24.3}-58.8^{\circ}\left(\mathrm{c} 0.17, \mathrm{CHCl}_{3}\right)$, lit. $[\alpha]_{D}-78.8^{\circ}$ (c 2.07, $\mathrm{CHCl}_{3}$ ) [12]; ${ }^{1} \mathrm{H}$ and ${ }^{13} \mathrm{C}$ NMR and UHPLC-MS data (see Figures S5-S7).

\subsection{X-ray Crystallography Analysis of Dysideathiazole}

Intensity data for dysideathiazole (2) were collected using an Oxford Diffraction Synergy diffractometer with $\mathrm{Cu}-\mathrm{K} \alpha$ radiation. An Oxford Cryosystems cooling device maintained the temperature at $100.0 \mathrm{~K}$ throughout the experiment. The structure was solved by direct methods and difference Fourier synthesis [23]. Hydrogen atoms were placed in their idealized positions and included in subsequent refinement cycles. Hydrogen atoms attached to heteroatoms were located from different Fourier maps and freely refined with isotropic displacement parameters. Thermal ellipsoid plots were generated in Mercury within the WINGX suite of programs [24,25]. The absolute configuration of dysideathiazole (2) was confirmed directly by the experiments detailed by Parson et al. [26].

Dysideathiazole (2): $\mathrm{T}=100.0(10) \mathrm{K}, \lambda=1.54184 \AA$, Orthorhombic, space group $\mathrm{P}$ $2{ }_{1} 2_{1} 2_{1} a=9.4921(1), b=10.4893(1), c=19.7454(1) \AA, V=1965.96(2) \AA^{3}, Z=4$, $D_{c}=1.558 \mathrm{Mg} \mathrm{M}^{-3} \mu(\mathrm{Cu}-\mathrm{K} \alpha)=9.001 \mathrm{~mm}^{-1}, F(000)=936$, crystal size $0.31 \times 0.19 \times 0.13 \mathrm{~mm}^{3}$. $\theta_{\max }=77.30^{\circ}, 68906$ reflections measured, 4143 independent reflections $\left(R_{\text {int }}=0.0649\right)$ with $R_{\text {final }}=0.0246[I>2 \sigma(I), 4099$ reflections $]$ and $w R\left(F^{2}\right)=0.0651$ (all data), GOOF $=1.015$. Absolute structure parameter: 0.002(12).

\subsection{Preparation of Parasitic Nematode Larvae for Bioassays}

The anthelmintic effects of fractions and purified compounds were tested on larvae of $H$. contortus (Haecon-5 strain). L3s were produced and stored using a well-defined protocol [11] - approved by the animal ethics committee of the University of Melbourne (permit no. 1714374). For use in the assay, L3s were exsheathed and sterilised by incubation in $0.15 \%(v / v)$ sodium hypochlorite $(\mathrm{NaClO})$ at $38^{\circ} \mathrm{C}$ for $20 \mathrm{~min}[27]$ and then washed five times in sterile saline by centrifugation at $500 \times g(5 \mathrm{~min})$ at room temperature $\left(22-24{ }^{\circ} \mathrm{C}\right)$. After the last wash, exsheathed L3s (i.e., xL3s) were suspended in Luria-Bertani broth (LB) containing $100 \mathrm{IU} / \mathrm{mL}$ of penicillin, $100 \mu \mathrm{g} / \mathrm{mL}$ of streptomycin and $0.25 \mu \mathrm{g} / \mathrm{mL}$ of amphotericin B (Fungizone; Thermo Fisher Scientific)—designated LB*. In vitro-raised L4s were produced by culturing xL3s for $168 \mathrm{~h}$ in $\mathrm{LB}^{*}$ at $38^{\circ} \mathrm{C}, 10 \%(v / v) \mathrm{CO}_{2}$ and a relative humidity of $>90 \%$.

\subsection{Bioassay for the Assessment of Anthelmintic Activity of Citronia Extract-Fractions}

Individual fractions ( $n=60)$ (Section 3.3) were tested for their anthelmintic effect on larvae (xL3s) of $H$. contortus using an established bioassay [11]. The assay was performed in triplicate. In brief, fractions in $40 \mu \mathrm{L}$ of $\mathrm{LB}^{*}(2000 \mu \mathrm{ge} / \mu \mathrm{L})$ were dispensed into the wells of sterile 368-well flat-bottom microtitre plates (cat. no. 3680; Corning, Corning, NY, USA) containing $80 \mathrm{xL} 3 \mathrm{~s}$; quadruplicate wells with no compound (LB* $+0.6 \%$ DMSO; negative control) or monepantel (Zolvix; Elanco, Greenfield, IN, USA), moxidectin (Cydectin; Virbac, Carros, France), monepantel/abamectin (Zolvix Plus; Elanco, Greenfield, IN, USA) and compound MIPS-0018666 (abbreviated here as M-666; ref. [28]) as positive-controls (20 $\mu \mathrm{M})$. The motility of xL3s was measured at $90 \mathrm{~h}$, and the development and phenotypic alterations of xL3s at $168 \mathrm{~h}$. At $168 \mathrm{~h}$, larvae in individual wells were fixed with $40 \mu \mathrm{L}$ of $1 \%$ iodine and microscopically examined using a M80 light microscope (Leica, Wetzlar, Germany) at 60-times magnification to assess their development based on the presence or absence of a well-developed pharynx [27], as well as their morphology (phenotype) [7,11]. At $168 \mathrm{~h}$, $\mathrm{xL} 3 \mathrm{~s}$ exposed to $\mathrm{LB}^{*}$ with $\leq 0.6 \% \mathrm{DMSO}$ are expected to reach the $\mathrm{L} 4$ stage in vitro within $168 \mathrm{~h}$ [10]. 


\subsection{Bioassay for the Evaluation of Anthelmintic Activity of Purified Compounds}

The compounds, dysidenin (1) and dysideathiazole (2) were individually tested for their anthelmintic effect on larvae (xL3s or in vitro-raised L4s) of $H$. contortus using an established bioassay [27]. Each assay was performed in triplicate on three different days. In brief, compounds were serially diluted in $50 \mu \mathrm{L}$ of $\mathrm{LB}^{*}$ (18-points, 2-fold dilution, $100 \mu \mathrm{M}$ to $0.76 \mathrm{nM}$ ) and dispensed into the wells of sterile 96-well flat-bottom microtitre plates (cat. no. 3596; Corning) containing 300 xL3s or L4s; with six wells with no compound $\left(\mathrm{LB}^{*}+0.25 \%\right.$ DMSO; negative control). A plate containing serial dilutions of monepantel (positive control) was prepared in the same manner. The motility of larvae was measured at $72 \mathrm{~h}$, and the development and phenotypic alterations of xL3s at $168 \mathrm{~h}$. At $168 \mathrm{~h}$, larvae in individual wells were fixed with $25 \mu \mathrm{L}$ of $1 \%$ iodine and microscopically examined using a DM1000 LED microscope (Leica, Wetzlar, Germany) at 100-times magnification to assess their development based on the presence or absence of a well-developed pharynx [27], as well as their morphology (phenotype) [7,11].

Supplementary Materials: The following are available online at https://www.mdpi.com/article/ 10.3390/md19120698/s1, Figure S1: C18 HPLC chromatogram of the Citronia sp. extract with anthelmintic activity. Figure S2: 1H NMR (800 MHz) spectrum of dysidenin (1) in CDCl3. Figure S3: 13C NMR (200 MHz) spectrum of dysidenin (1) in CDCl3. Figure S4: UHPLC-MS data for dysidenin (1). Figure S5: 1H NMR ( $800 \mathrm{MHz}$ ) spectrum of dysideathiazole (2) in CDCl3. Figure S6: 13C NMR (200 MHz) spectrum of dysideathiazole (2) in CDCl3. Figure S7: UHPLC-MS data for dysideathiazole (2). Figure S8: Crystal packing drawing of dysideathiazole (2).

Author Contributions: Conceptualisation, R.B.G., R.A.D. and A.J.; methodology, A.C.T., R.B.G. and R.A.D.; validation, A.C.T. and J.J.B.; formal analysis, R.B.G., A.C.T., R.A.D., J.J.B., K.Y.L. and K.S.R.; investigation, A.C.T., J.J.B., K.Y.L. and K.S.R.; resources, A.C.T., J.J.B., A.J., T.W., K.S.R., S.H., J.M.W., M.G.E., R.A.D. and R.B.G.; data curation, A.C.T., J.J.B., K.Y.L., J.M.W., R.A.D. and K.S.R.; writingoriginal draft preparation, R.B.G., A.C.T., K.S.R., K.Y.L. and R.A.D.; writing-review and editing, A.C.T., J.J.B., A.J., K.Y.L., K.S.R., S.H., M.G.E., J.M.W., T.W., A.H., R.A.D. and R.B.G.; visualisation, A.C.T. and R.A.D.; supervision, R.B.G. and R.A.D.; project administration, R.B.G., A.J., R.A.D. and A.C.T.; funding acquisition, R.B.G., R.A.D. and A.J. All authors have read and agreed to the published version of the manuscript.

Funding: This study was supported by the Australian Research Council (ARC) and Phylumtech S.A. (Argentina).

Institutional Review Board Statement: The study was conducted according to the guidelines of the Declaration of Helsinki, and approved by the Institutional Review Board (Animal Ethics Committee) of The University of Melbourne (permit no. 1714374).

Data Availability Statement: The data presented in this study are available in the article.

Acknowledgments: We are grateful to Compounds Australia for curating and shipping the NatureBank marine extract library.

Conflicts of Interest: The authors declare that they have no conflict of interest. Neither the funding body nor the industry partner played a role in the design of the study, collection, analysis or interpretation of data, in the writing of the manuscript or in the decision to publish the results.

\section{References}

1. Roeber, F.; Jex, A.R.; Gasser, R.B. Impact of gastrointestinal parasitic nematodes of sheep, and the role of advanced molecular tools for exploring epidemiology and drug resistance-an Australian perspective. Parasit. Vectors 2013, 6, 153. [CrossRef] [PubMed]

2. Beveridge, I.; Emery, D. Australian Animal Parasites—Inside and Out; The Australian Society for Parasitology Inc.: Smithfield, Australia, 2014; ISBN 9780646935607.

3. Kotze, A.C.; Prichard, R.K. Anthelmintic resistance in Haemonchus contortus: History, mechanisms and diagnosis. Adv. Parasitol. 2016, 93, 397-428.

4. Besier, R.B.; Kahn, L.P.; Sargison, N.D.; Van Wyk, J.A. Diagnosis, treatment and management of Haemonchus contortus in small ruminants. Adv. Parasitol. 2016, 93, 181-238. 
5. Herath, H.M.P.D.; Taki, A.C.; Sleebs, B.E.; Hofmann, A.; Nguyen, N.; Preston, S.; Davis, R.A.; Jabbar, A.; Gasser, R.B. Advances in the discovery and development of anthelmintics by harnessing natural product scaffolds. Adv. Parasitol. 2021, 111, 203-251. [PubMed]

6. Jiao, Y.; Preston, S.; Hofmann, A.; Taki, A.C.; Baell, J.B.; Chang, B.C.H.; Jabbar, A.; Gasser, R.B. A perspective on the discovery of selected compounds with anthelmintic activity against the barber's pole worm-Where to from here? Adv. Parasitol. 2020, 108, 1-45. [PubMed]

7. Taki, A.C.; Byrne, J.J.; Jabbar, A.; Lum, K.Y.; Hayes, S.; Addison, R.S.; Ramage, K.S.; Hofmann, A.; Ekins, M.G.; Wang, T.; et al. High Throughput Screening of the NatureBank 'Marine Collection' in a Haemonchus Bioassay Identifies Anthelmintic Activity in Extracts from a Range of Sponges from Australian Waters. Molecules 2021, 26, 5846. [CrossRef]

8. Carroll, A.R.; Pierens, G.K.; Fechner, G.; de Almeida Leone, P.; Ngo, A.; Simpson, M.; Hyde, E.; Hooper, J.N.A.; Boström, S.-L.; Musil, D.; et al. Dysinosin A: A Novel Inhibitor of Factor VIIa and Thrombin from a New Genus and Species of Australian Sponge of the Family Dysideidae. J. Am. Chem. Soc. 2002, 124, 13340-13341. [CrossRef] [PubMed]

9. Carroll, A.R.; Duffy, S.; Avery, V.M. Citronamides A and B, Tetrapeptides from the Australian Sponge Citronia astra. J. Nat. Prod. 2009, 72, 764-768. [CrossRef] [PubMed]

10. Herath, H.; Preston, S.; Jabbar, A.; García-Bustos, J.; Taki, A.; Addison, R.; Hayes, S.; Beattie, K.; McGee, S.; Martin, S.; et al. Identification of fromiamycalin and halaminol A from Australian marine sponge extracts with anthelmintic activity against Haemonchus contortus. Mar. Drugs 2019, 17, 598. [CrossRef]

11. Taki, A.C.; Byrne, J.J.; Wang, T.; Sleebs, B.E.; Nguyen, N.; Hall, R.S.; Korhonen, P.K.; Chang, B.C.H.; Jackson, P.; Jabbar, A.; et al. High-throughput phenotypic assay to screen for anthelmintic activity on Haemonchus contortus. Pharmaceuticals 2021, 14, 616. [CrossRef] [PubMed]

12. Unson, M.D.; Rose, C.B.; Faulkner, D.J.; Brinen, L.S.; Steiner, J.R.; Clardy, J. New polychlorinated amino acid derivatives from the marine sponge Dysidea herbacea. J. Org. Chem. 1993, 58, 6336-6343. [CrossRef]

13. Kazlauskas, R.; Lidgard, R.; Wells, R.; Vetter, W. A novel hexachloro-metabolite from the sponge Dysidea herbacea. Tetrahedron Lett. 1977, 18, 3183-3186. [CrossRef]

14. Biskupiak, J.E.; Ireland, C.M. Revised absolute configuration of dysidenin and isodysidenin. Tetrahedron Lett. 1984, 25, $2935-2936$. [CrossRef]

15. Taki, A.C.; Brkljača, R.; Wang, T.; Koehler, A.V.; Ma, G.; Danne, J.; Ellis, S.; Hofmann, A.; Chang, B.C.H.; Jabbar, A.; et al. Natural compounds from the marine brown alga Caulocystis cephalornithos with potent in vitro-activity against the parasitic nematode Haemonchus contortus. Pathogens 2020, 9, 550. [CrossRef] [PubMed]

16. Van Sande, J.; Deneubourg, F.; Beauwens, R.; Braekman, J.C.; Daloze, D.; Dumont, J.E. Inhibition of iodide transport in thyroid cells by dysidenin, a marine toxin, and some of its analogs. Mol. Pharmacol. 1990, 37, 583-589.

17. Van Sande, J.; Massart, C.; Beauwens, R.; Schoutens, A.; Costagliola, S.; Dumont, J.; Wolff, J. Anion selectivity by the sodium iodide symporter. Endocrinology 2003, 144, 247-252. [CrossRef]

18. Vroye, L.; Beauwens, R.; Van Sande, J.; Daloze, D.; Braekman, J.; Golstein, P. The $\mathrm{Na}^{+}-\mathrm{I}-$ cotransporter of the thyroid: Characterisation of new inhibitors. Pflüg. Arch. 1997, 435, 259-266. [CrossRef]

19. Lindenthal, S.; Lecat-Guillet, N.; Ondo-Mendez, A.; Ambroise, Y.; Rousseau, B.; Pourcher, T. Characterization of small-molecule inhibitors of the sodium iodide symporter. J. Endocrinol. 2009, 200, 357-365. [CrossRef]

20. Deschamps, J.D.; Gautschi, J.T.; Whitman, S.; Johnson, T.A.; Gassner, N.C.; Crews, P.; Holman, T.R. Discovery of platelet-type 12-human lipoxygenase selective inhibitors by high-throughput screening of structurally diverse libraries. Bioorg. Med. Chem. 2007, 15, 6900-6908. [CrossRef]

21. Yamazaki, H.; Ohte, S.; Rotinsulu, H.; Wewengkang, D.S.; Sumilat, D.A.; Abdjul, D.B.; Maarisit, W.; Kapojos, M.M.; Namikoshi, M.; Katagiri, T.; et al. Screening for small molecule inhibitors of BMP-induced osteoblastic differentiation from Indonesian marine invertebrates. Mar. Drugs 2020, 18, 606. [CrossRef]

22. Charles, C.; Braekman, J.C.; Daloze, D.; Tursch, B.; Karlsson, R. Isodysidenin, a further hexachlorinated metabolite from the sponge Dysidea herbacea. Tetrahedron Lett. 1978, 17, 1519-1520. [CrossRef]

23. Sheldrick, G. Crystal structure refinement with SHELXL. Acta Crystallogr. C 2015, 71, 3-8. [CrossRef] [PubMed]

24. Macrae, C.F.; Bruno, I.J.; Chisholm, J.A.; Edgington, P.R.; McCabe, P.; Pidcock, E.; Rodriguez-Monge, L.; Taylor, R.; Van De Streek, J.; Wood, P. A, Mercury CSD 20-New features for the visualization and investigation of crystal structures. J. Appl. Crystallogr. 2008, 41, 466-470. [CrossRef]

25. Farrugia, L. WinGX suite for small-molecule single-crystal crystallography. J. Appl. Crystallogr. 1999, 32, 837-838. [CrossRef]

26. Parsons, S.; Flack, H.D.; Wagner, T. Use of intensity quotients and differences in absolute structure refinement. Acta Crystallogr. $B$ Struct. Sci. Cryst. Eng. Mater. 2013, 69, 249-259. [CrossRef]

27. Preston, S.; Jabbar, A.; Nowell, C.; Joachim, A.; Ruttkowski, B.; Baell, J.; Cardno, T.; Korhonen, P.K.; Piedrafita, D.; Ansell, B.R.; et al. Low cost whole-organism screening of compounds for anthelmintic activity. Int. J. Parasitol. 2015, 45, 333-343. [CrossRef] [PubMed]

28. Le, T.G.; Kundu, A.; Ghoshal, A.; Nguyen, N.H.; Preston, S.; Jiao, Y.; Ruan, B.; Xue, L.; Huang, F.; Keiser, J.; et al. Optimization of novel 1-methyl-1 h -pyrazole-5-carboxamides leads to high potency larval development inhibitors of the barber's pole worm. J. Med. Chem. 2018, 61, 10875-10894. [CrossRef] 